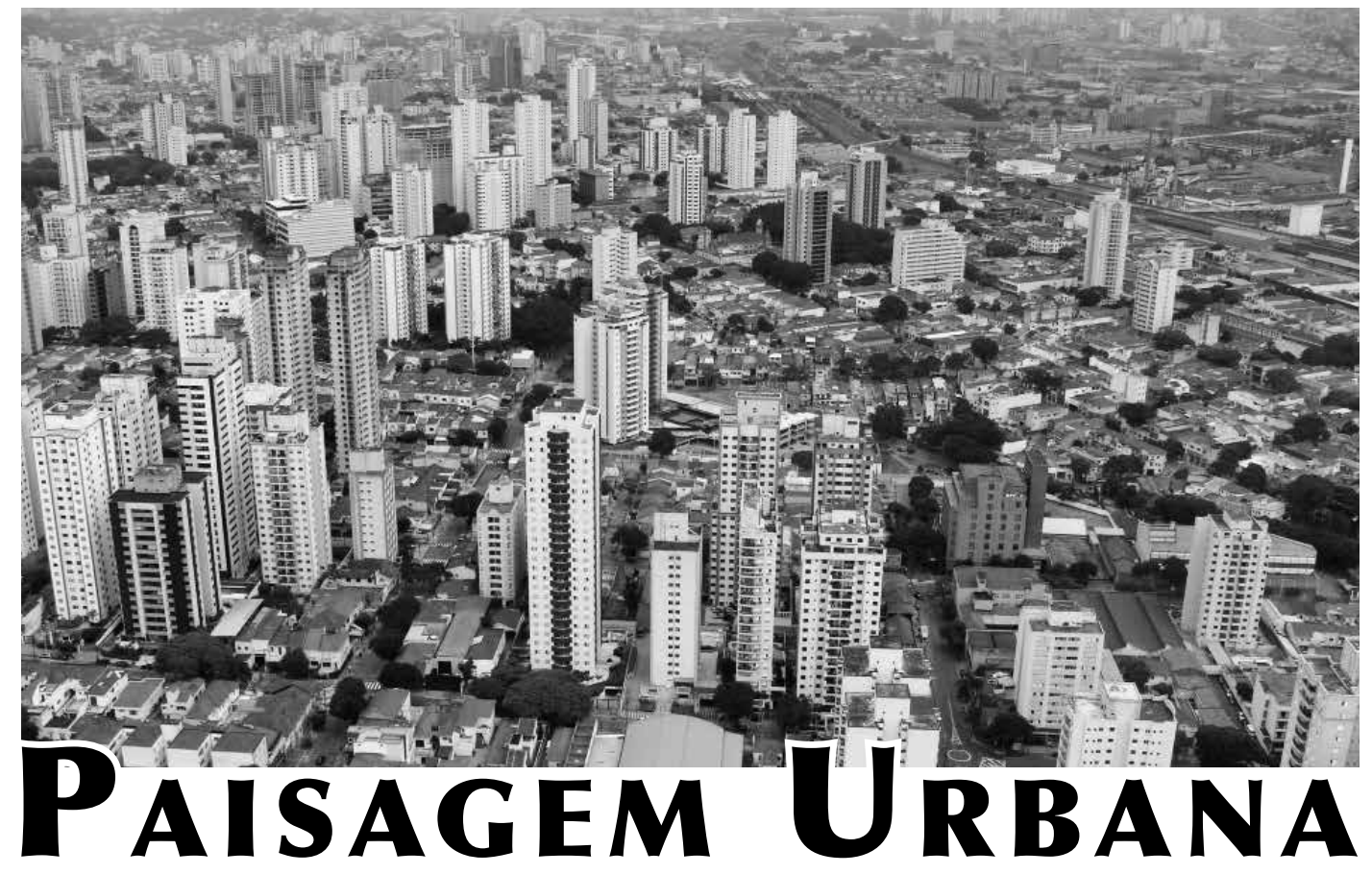




\title{
ESPAÇOS LIVRES DA HABITAÇÃO VERTICALIZADA EM SÃO PAULO: ESTUDO DE CASO DA VILA ROMANA
}

\author{
OPEN SPACES OF VERTICAL HOUSING IN SAO PAULO: VILA ROMANA CASE
}

\begin{abstract}
Luciana Satiko Takaesu
Arquiteta e urbanista pela Universidade de São Paulo e mestranda do curso de pós-graduação em Arquitetura e Urbanismo da Universidade de São Paulo, área de concentração Paisagem e Ambiente e-mail: luciana.takaesu@usp.br
\end{abstract}

\section{RESUMO}

O texto apresenta a pesquisa realizada junto ao Laboratório QUAPA - Quadro do Paisagismo no Brasil - da FAUUSP. O objeto deste estudo é o fenômeno da verticalização na cidade de São Paulo, mais precisamente a produção habitacional recente, analisando o projeto de seus espaços livres do ponto de vista programático e espacial e sua influência na formação do sistema de espaços livres.

Grandes conjuntos de apartamentos estão sendo construídos e vendidos em São Paulo, ao mesmo tempo em que tipos consolidados - como a torre isolada centralizada no lote, cercada de equipamentos de recreação, permanecem como opção. Isso implica em um aumento de emprego de equipamentos de lazer, crescendo em número e variedade, que rapidamente passam da categoria de inovação à necessidade, alterando o projeto dos espaços livres.

Campanhas publicitárias usam dos espaços "verdes", tratamento paisagístico e áreas de lazer para vender apartamentos. Toda essa produção altera a paisagem da cidade. $\bigcirc$ estudo dos agentes da produção do espaço, especialmente da legislação e do mercado imobiliário nos permite entender o desenho desses espaços. $O$ bairro da Vila Romana é um exemplo desse fenômeno e foi escolhido como estudo de caso. $\bigcirc$ aumento do porte dos conjuntos residenciais e da complexidade do programa de seus espaços livres trazem novas possibilidades de desenho, com novas formas de apropriação e percepção dos espaços, públicos e privados, e, por fim, da cidade.

Palavras-chave: Verticalização, São Paulo, Projeto paisagístico, Espaços livres

\begin{abstract}
This paper presents a research linked to the QUAPA Laboratory - Brazil's Landscaping Portrait, from the FAUUSP. The object of this study is the São Paulo verticalization phenomena, more precisely the housing production, analyzing its open spaces from the programmatic and spatial point of view and its influence in the city's open spaces system formation during the 1994 - 2007 period.

Large apartament buildings complexes were constructed and sold in São Paulo, while consolidated typologies, such as the isolated centralized high-hise surrounded by recreation equipment were kept as a option. Those construction undertakings increasily employed more leisure equipaments expanding its numbers and variety, and quickly they left the category of innovation to become a necessity, changing the design of its open spaces.

Advertising campaigns make use of the "green" spaces, landscaping design and leisure areas to sell apartments. All this production brings changes to the city landscape. The study of the space production agents, specially the government urban legislation and the real state market make us to understand the design of those spaces. Vila Romana neighborhood is a example of this phenomenon and has choosed a case study. The size expansion of the apartment building complexes and the increasing intricacy of its open spaces programs brings new design possibilities, with new ways of appropriation and perception, in the private and public spaces, and finally, in the city.
\end{abstract}

Keywords: Verticalization, São Paulo, Landscape design, Open spaces 


\section{INTRODUÇÃO}

O texto apresenta resultados de pesquisa de Iniciação Científica realizada junto ao Laboratório QUAPA, da FAUUSP. O objeto deste estudo é o fenômeno da verticalização na cidade de São Paulo, mais precisamente a produção habitacional recente, analisando o projeto de seus espaços livres do ponto de vista programático e espacial e sua influência na formação do sistema de espaços livres. Além do estudo da legislação urbanística e do mercado imobiliário, realizou-se o levantamento dos lançamentos residenciais dos anos 1994 até $2007^{1}$ para análise do desenho de seus espaços livres. Para o detalhamento do estudo, foi escolhida como estudo de caso uma área no bairro da Vila Romana.

São Paulo é uma das cidades em que o fenômeno da verticalização se deu de forma intensa e com destaque para o uso habitacional. Nos últimos anos, vê-se o lançamento de empreendimentos residenciais verticais de grande porte. Estes passaram a ocupar grandes terrenos, com um maior número de torres e aumento da variedade de equipamentos de lazer. A legislação da cidade, a partir de 1972, consolidou a implantação da torre isolada no lote e de equipamentos de lazer no térreo, configurando um padrão que foi importante na configuração da paisagem paulistana (MACEDO, 1987). Com a nova legislação urbanística, o mercado imobiliário aumentou sua atuação voltada para a produção residencial vertical em outras áreas, além da região mais valorizada, o vetor sudoeste.

Outro fator importante para as mudanças recentes na produção dos conjuntos residenciais verticais está ligado, entre outras variáveis, às mudanças no mercado financeiro, mais precisamente ao fenômeno de entrada das empresas de construção civil no mercado de ações. Este fato trouxe implicações tanto no número de lançamentos como no porte dos empreendimentos. Da mesma forma, implicou em inovações no produto "conjunto residencial vertical": equipamentos de lazer e estar, serviços ligados ao condomínio, novas estratégias de valorização e publicidade para a venda deste produto.

\section{PORTE E LOCALIZAÇÃO DOS EMPREENDIMENTOS ${ }^{2}$}

As mudanças na legislação com a aprovação do Plano Diretor Estratégico de São Paulo (Lei n. 13.430 de 2002) e da Lei de Zoneamento (Lei n. 13.885 de 2004) estimularam o mercado a produzir empreendimentos residenciais verticais em outras áreas, além do tradicional vetor sudoeste, área mais valorizada da cidade. Através do Plano Diretor Estratégico foram definidas as áreas em que se quer estimular a ocupação ou o adensamento. A cidade foi dividida em duas Macrozonas - de Proteção Ambiental e de Estruturação e Qualificação Urbana, e estas subdivididas em Macroáreas. A partir dessas diretrizes, os potenciais construtivos foram definidos nos Planos Regionais Estratégicos, elaborados pelas subprefeituras.

Através do mapa de Política de Desenvolvimento Urbano (figura 1), pode-se observar que a maior parte da região sudoeste, a mais valorizada da cidade, é classificada 


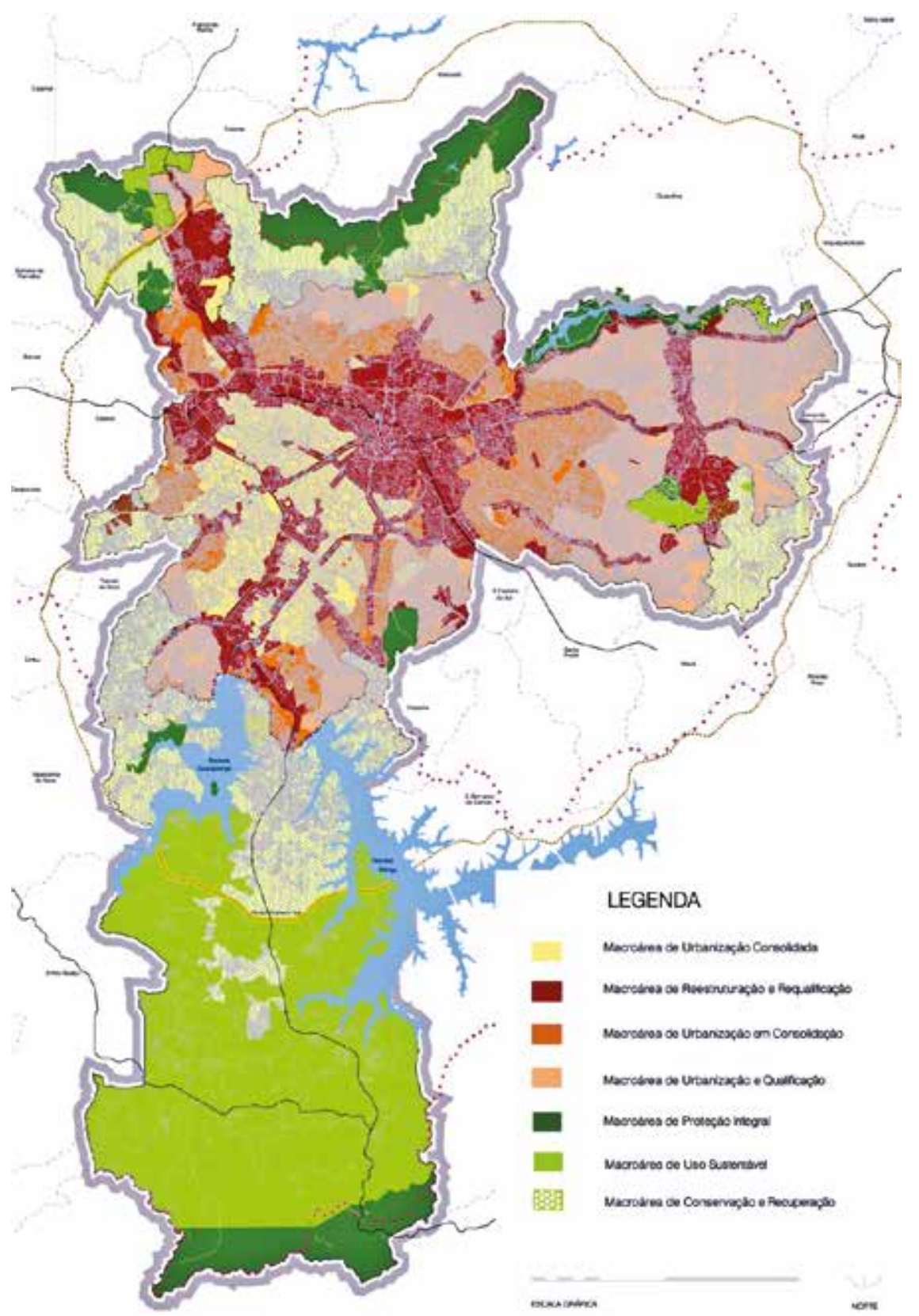

Figura 1 - Política de Desenvolvimento Urbano: Macroáreas.

Fonte: Plano Diretor Estratégico de São Paulo. 2002.

como consolidada (em amarelo), enquanto a diretriz de reestruturação e requalificação é definida para as outras regiões. Estas coincidem com as Áreas de Intervenção Urbana e os Perímetros das Operações Urbanas Consorciadas criadas na cidade, onde, pelo instrumento da Outorga Onerosa, o empreendedor obtém um acréscimo do potencial construtivo através do pagamento de uma contrapartida financeira. Há um estoque de potencial construtivo definido para cada distrito da cidade e pode-se observar o estímulo à verticalização de acordo com o estoque reservado para cada um deles. 
Outra alteração na legislação urbanística que influenciou a atuação do mercado em novas localizações está na Lei de Zoneamento em vigor que, ao retirar antigas áreas industriais da zona exclusivamente industrial, abriu para o mercado residencial áreas com grandes terrenos.

As mudanças na legislação, somadas a entrada das empresas de construção civil no mercado de ações, são o contexto para as mudanças na localização e porte dos lançamentos residenciais verticais. Além da busca do retorno para esse capital vindo das ações, as diretrizes da nova legislação incentivam novas frentes de verticalização que não o consolidado vetor sudoeste. $O$ mercado imobiliário investiu em novas localizações, em busca de grandes terrenos e menor valor da terra, apropriando-se do porte do terreno para a implantação de equipamentos de lazer, valorização do tratamento paisagístico e do "contato com a natureza".

Ainda sim, a produção de pequenos conjuntos residenciais verticais, com o padrão de implantação da torre isolada no lote, padrão em São Paulo, ainda é recorrente. Tampouco o vetor sudoeste deixou de ser o mais valorizado. Essas são tendências, do mercado imobiliário, consolidadas e ainda atrativas. Os processos intensos de verticalização da última década, fora do eixo de investimento consolidado do vetor sudoeste, constituem nichos de mercado definidos para os segmentos econômicos de renda média e alta, como ocorre na zona leste e norte de São Paulo, por exemplo. Outro fenômeno pode ser observado na zona oeste, como o surgimento de grandes empreendimentos imobiliários, dirigidos para moradia, na qual se selecionou o bairro da Vila Romana como estudo de caso.

\section{ATRIBUTOS DE VENDA DO "CONJUNTO RESIDENCIAL VERTICAL"}

Através dos anúncios de publicidade dos empreendimentos residenciais verticais, percebe-se como o produto é apresentado ao comprador, seja ele o consumidor final ou investidor. A partir da análise dos anúncios do acervo QUAPA foram elencados os principais atributos de mercado valorizados nos conjuntos residenciais verticais na cidade de São Paulo ${ }^{3}$. A definição dos principais atributos de mercado dos conjuntos residenciais verticais permite entender quais são as características dos empreendimentos que são viáveis e rentáveis para o mercado imobiliário e aceitas e desejadas pelo consumidor. Objetivo desse tipo de análise é estabelecer a relação entre esses atributos, que são valorizados atualmente, e a configuração dos espaços produzidos a partir da definição e valorização dos mesmos. Estes são os atributos que se destacam, isoladamente ou combinados.

- localização: o bairro, a proximidade de vias importantes da cidade, de ruas comerciais ou shoppings centers, equipamentos culturais, parques, colégios. A venda do atributo localização ocorre nos bairros de alta renda do vetor sudoeste da cidade, tradicionalmente considerados boa localização. Os conjuntos construídos em bairros como Higienópolis e Moema, por exemplo, não necessitam de uma variedade de equi- 
pamentos de lazer para tornarem-se atraentes. A própria localização já é valorizada. Outro exemplo são bairros que passaram por processo de verticalização, mas possuem ainda trechos de ocupação horizontal. Os anúncios de empreendimentos na região da Lapa, por exemplo, valorizam o bairro pelo seu casario tradicional. Os anúncios vendem a segurança e o lazer de um clube em meio a um bairro tradicional.

A denominação do bairro em que se localiza o conjunto residencial, a proximidade a uma via importante da cidade, a uma estação de Metrô ou a um parque, é realizada com o objetivo de mostrar que o empreendimento é bem localizado. Além das chamadas do tipo "More no Jardim da Saúde" ou "a 5 minutos do Zoológico", são comuns mapas de localização sem escala, sem proporção.

- área verde ou "contato com a natureza": valorização da existência de área verde, seja interna ou externa ao conjunto residencial. Esta última refere-se à proximidade a parques, praças e relaciona-se com o atributo acima, pois remete à localização do empreendimento. A valorização da área verde ocorre em todos os portes de empreendimentos, sejam os pequenos conjuntos de uma torre ou nos conjuntos implantados em grandes glebas. Nos primeiros, é comum encontrar quatro ou cinco árvores reunidas com o nome de "bosque" ou "pomar". Já em conjuntos implantados em grandes terrenos, em áreas de interesse recente pelo mercado, os conjuntos têm parte do terreno arborizada, pistas de cooper e áreas para ginástica entre as árvores.

Esta área verde, dentro do lote, é um item valorizado no empreendimento, mas também deve ser entendida como uma apropriação do empreendedor, por ser obrigado a manter áreas vegetadas existentes nos terrenos, ou implantar vegetação de acordo com as leis de compensação ambiental.

- lazer: variada gama de equipamentos e espaços de lazer e convívio. Processo observado desde os anos 1970, a diversificação dos equipamentos e ambientes de uso coletivo atingiu maior rapidez no final dos anos 1990, num processo de inovação constante em que as novidades passam rapidamente a se tornar itens obrigatórios nos conjuntos residenciais.

Os anúncios vendem a ideia de se "morar em um clube", com equipamentos e espaços de lazer, tanto na área externa ou interna, ocupando o térreo. São espaços para o uso individual ou em grupo, estes últimos caracterizados pelos espaços de convivência que se diversificaram nos últimos anos. Para Villa, esses ambientes não constituem inovações: são derivações do tradicional salão de festas, que ganhou nomes e espaços para cada faixa etária ou tipo de atividade. (VILLA, 2008). Entre os novos itens relacionados aos usos que podem ser dados ao térreo estão facilidades como os serviços pay per use e os ambientes para prestação de serviços como o beauty care, pet care, bares e cafés.

- planta/fachada do apartamento: o anúncio vende o requinte, status, glamour de se morar em um edifício de estilo "tal" ou com um apartamento grande. Geralmente, o térreo não possui tantos itens de lazer como no item acima. Observou-se que a imagem da fachada é mais recorrente nos anúncios que o desenho da planta do apartamento. 
A partir da metade da década de 1990, as plantas dos apartamentos se tornaram tão semelhantes que passaram a ser suprimidas dos anúncios imobiliários (VILLA, 2002). Pode-se acrescentar a esse motivo o processo de valorização dos espaços de uso coletivo, fazendo com que os desenhos dos espaços coletivos tomassem o lugar das plantas de apartamento nos anúncios.

A planta aparece em destaque apenas quando esse é o atributo mais importante do emprendimento. Em grande parte desses casos, os apartamentos são grandes - 3 dormitórios ou mais - possuem vários ambientes sociais (sala de estar, sala íntima, sala de jantar, sala de almoço, "amplo terraço", family room) e de uso íntimo (3 ou 4 suítes, áreas mais generosas nos banheiros e closets). Nesses apartamentos são comuns as opções de planta para converter uma das salas em dormitório ou o quarto de empregada em home office, por exemplo.

\section{VILA ROMANA: ESTUDO DE CASO}

A Vila Romana é um bairro que se encontra, nesta primeira década do século XXI, em um processo de verticalização, com características recorrentes em outras regiões da cidade. As características em relação à localização, porte e quantidade dos conjuntos, podem ser encontradas em outros núcleos de verticalização paulistanos, assim como suas implicações na transformação do espaço urbano. Também são semelhantes as

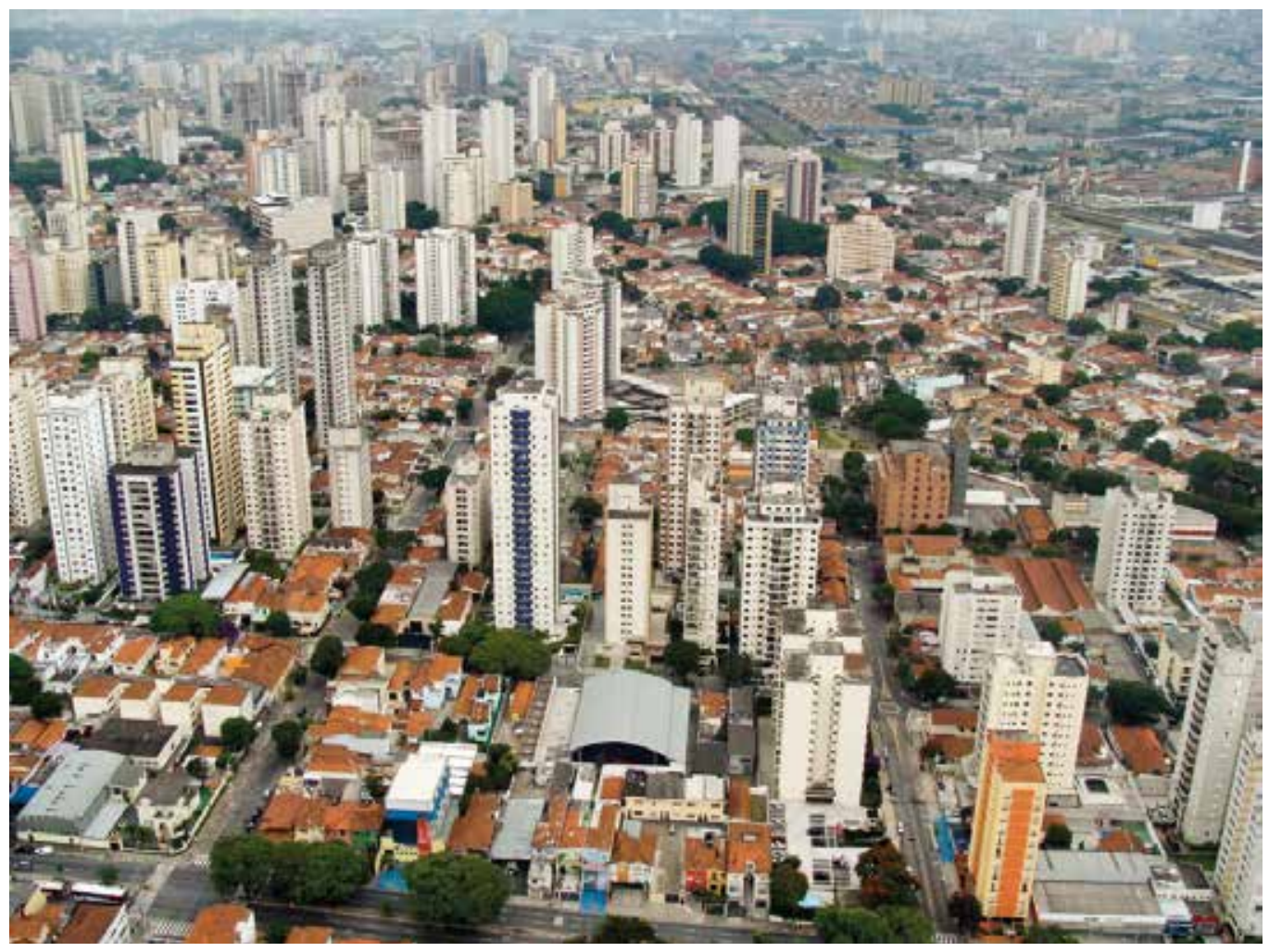

Figura 2 - Vista aérea da área de estudo. Sobrevoo realizado em fevereiro de 2008. Fonte: Acervo QUAPA 
características da configuração do espaço no interior dos conjuntos, como a implantação dos edifícios e o programa do térreo desses conjuntos, com equipamentos de lazer e áreas ajardinadas.

O bairro situa-se na zona oeste de São Paulo e está entre aqueles em que se observa um fenômeno de verticalização fora do eixo sudoeste da cidade. A verticalização da região da Vila Romana ocorre a partir do remembramento de lotes, em que terrenos com casas térreas e sobrados, ou ocupados anteriormente por indústrias, dão lugar a grandes condomínios. Alguns ocupam meia quadra ou a quadra inteira, gerando faces de quadra totalmente muradas. O processo é, assim, de substituição dos sobrados e galpões característicos da região por grandes lotes com características de clubes. Constitui um dos eixos de verticalização de valorização recente e tem combinados o incentivo da legislação urbanística e o interesse do mercado imobiliário em investir na região.

Na Política de Desenvolvimento Urbano, definida pelo Plano Diretor Estratégico de São Paulo, de 2004, a área é classificada como Macroárea de Reestruturação e Qualificação. Umas das intenções, em áreas desse tipo, é a promoção imobiliária, utlilzando, entre outros instrumentos, as Operações Urbanas Consorciadas, incluindo a outorga onerosa do direito de construir.

A região está delimitada no PRE da Lapa como parte da Operação Urbana Diagonal Norte e Água Branca (figura 3). O município, como pode-se observar, tem dado incentivos à promoção imobiliária na região através de seus instrumentos urbanísticos. O distrito da Lapa, ao qual pertence a área, estava, no final do ano de 2007, entre os distritos que possuíam os maiores percentuais de estoques construtivos já compro-

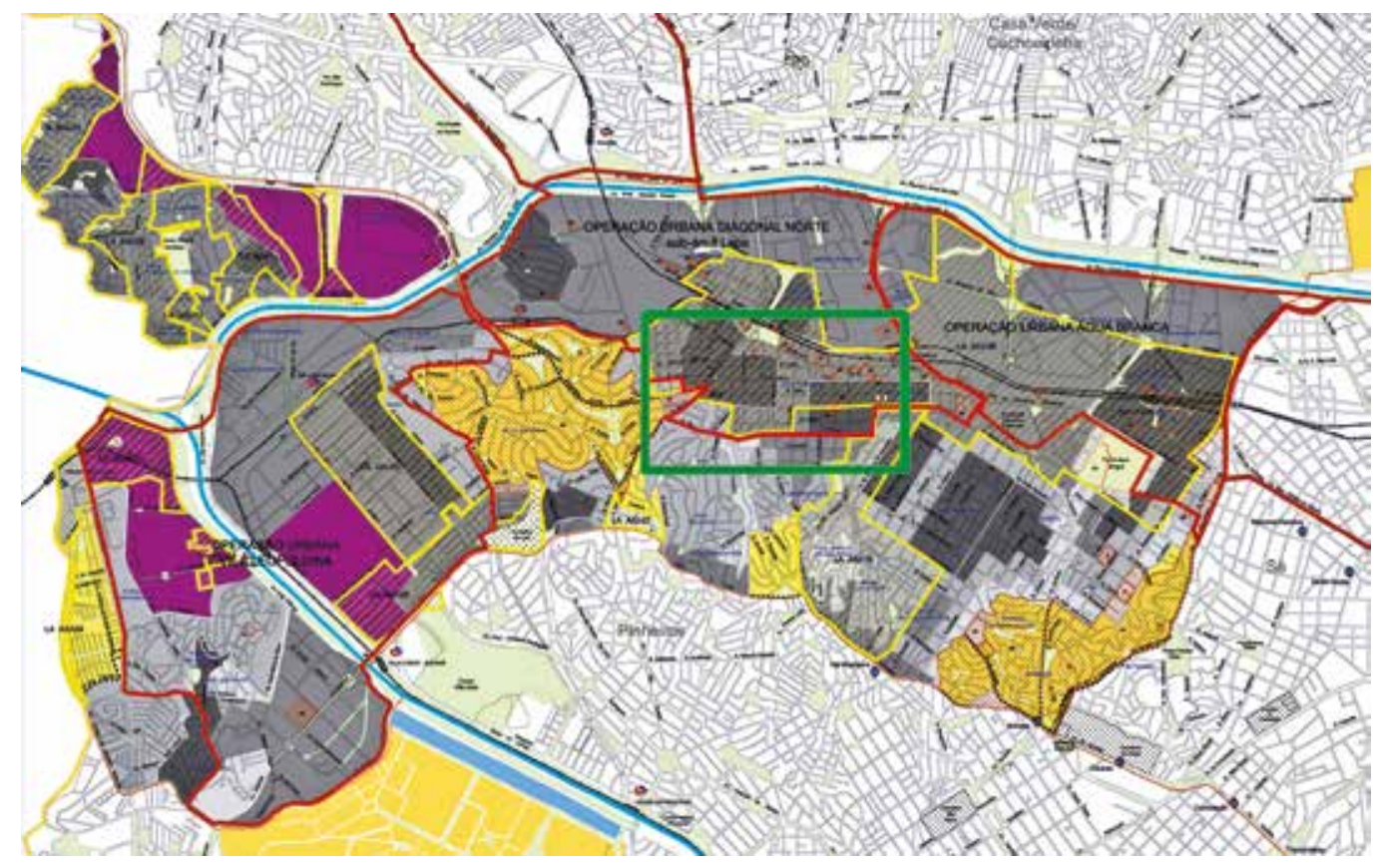

Figura 3 - Operação Urbana Diagonal Norte e Operação Urbana Água Branca.

Plano Regional Estratégico (PRE) da Subprefeitura da Lapa. 2004. Em verde, indicação da foto aérea da figura 4. 
metidos do município, com 63\% de total disponibilizado $\left(75.000 \mathrm{~m}^{2}\right)^{4}$. $\bigcirc$ mercado imobiliário encontrou, então, uma região com potencial construtivo atraente e com um tipo de ocupação - casarios e galpões - passível de ser demolido e substituído por conjuntos residenciais.

Foi delimitada uma área de estudo que, segundo o Zoneamento de 2004, pertence às zonas ZM3 - Zona Mista de Alta Densidade, do tipo a e b. São as zonas que mais favorecem a verticalização, por possuírem o maior coeficiente de aproveitamento (coeficiente máximo de 2,50) e por não possuírem limite de gabarito. A concentração dos empreendimentos ocorre nas quadras adjacentes à Rua Fábia, principalmente no perímetro da zona ZM3b, que possui coeficiente de aproveitamento básico maior em relação à zona ZM3a (figuras 4 e 5).

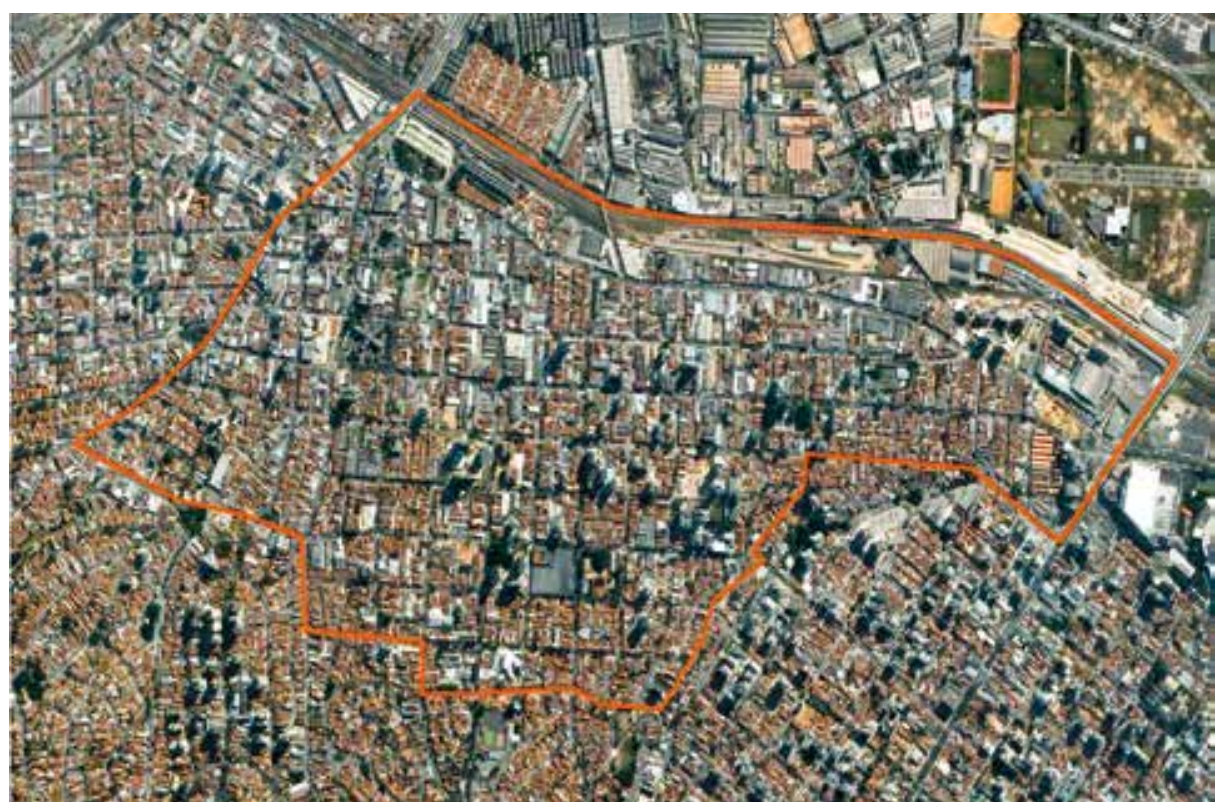

Figura 4 - Vila Romana. Estudo de caso.

Fonte: Google Earth. 2007

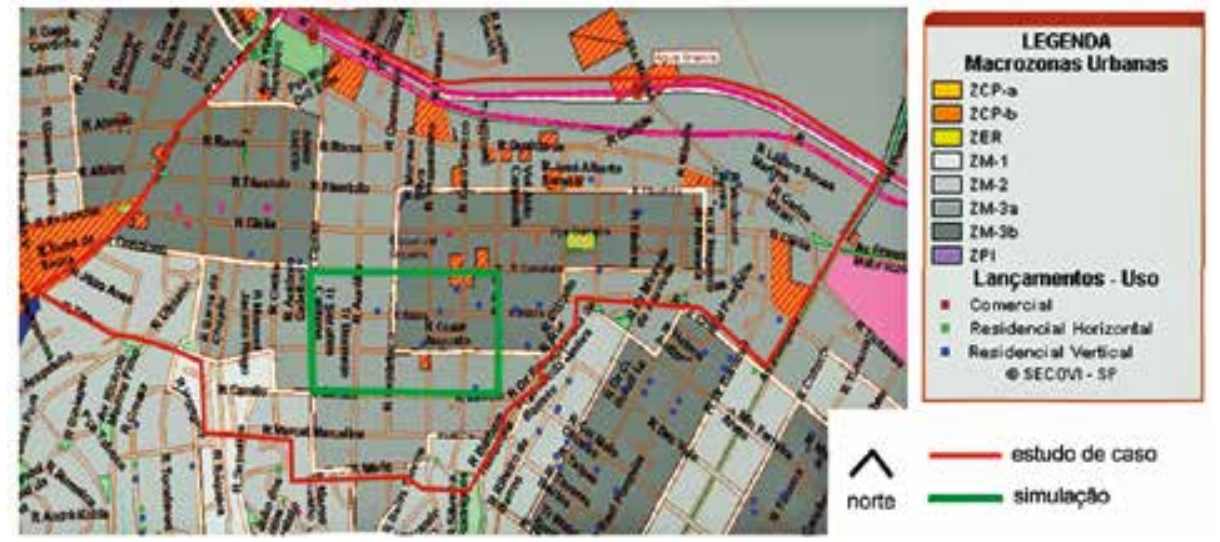

Figura 5 - Vila Romana. Lançamentos de dezembro de 1997 a julho de 2007. Fonte: SECOVI-SP 
Foi escolhido um trecho para a realização de uma simulação do potencial de transformação da área, de acordo com a legislação vigente. O relevo foi considerado plano, pois o desnível, de 20 metros (entre os pontos mais distantes do trecho delimitado), não confere ao local uma inclinação considerada acentuada (cerca de 3\%).

O trecho engloba quadras adjacentes à Rua Fábia, onde se observam o maior número de lançamentos residenciais verticais, indicados em azul na figura 5. Engloba também quadras ao sul destas, onde já se observa um "espraiamento" desses lançamentos. A delimitação do trecho considerou também o zoneamento, englobando as zonas existentes na área do estudo de caso:

Tabela 1: Coeficientes de aproveitamento da simulação da Lei de Zoneamento.

\begin{tabular}{l|l|l|l}
\hline Zona/Coeficiente & Mínimo & Básico & Máximo \\
\hline ZM 3a & 0,2 & 1,0 & 2,5 \\
\hline ZM 3b & 0,2 & 2,0 & 2,5 \\
\hline
\end{tabular}

Fonte: PRE Lapa. 2004

A simulação permite concluir que a transformação da região, através do processo de verticalização, segundo a legislação vigente, pode gerar um tecido urbano homogêneo, mesmo constituída de zonas com coeficientes de aproveitamento diferentes. Permite concluir, também, que há grande potencial de transformação da paisagem, pois os coeficientes de aproveitamento adotados para a área permitem a "reprodução do solo urbano" em uma região que, tradicionalmente, é ocupada por construções térreas ou sobrados (casario e galpões industriais, principalmente). Este grande potencial de transformação pode alterar inclusive a caracterísitca de "bairro tradicional", que é valorizada pelo mercado imobiliário nos anúncios de empreendimentos desta região, pois o processo é de demolição de casas e sobrados, com remembramento de lotes, para dar lugares a conjuntos que ocupam boa parte da quadra e, por vezes, a quadra inteira.

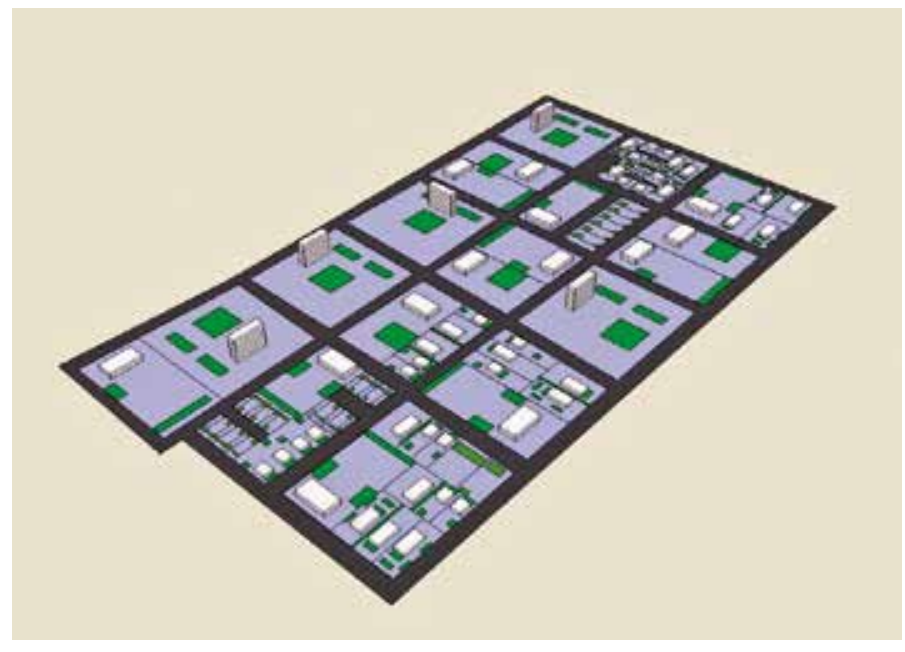

Figura 6 - Vila Romana.

Simulação da Lei de Zoneamento de 2004. Coeficiente Mínimo. Fonte: Acervo QUAPA 


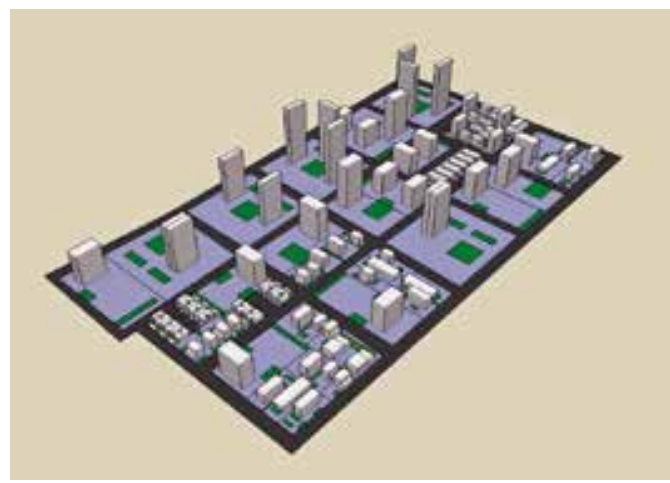

Figura 7 - Vila Romana. Simulação da Lei de Zoneamento de 2004. Coeficiente Básico. Fonte: Acervo QUAPA

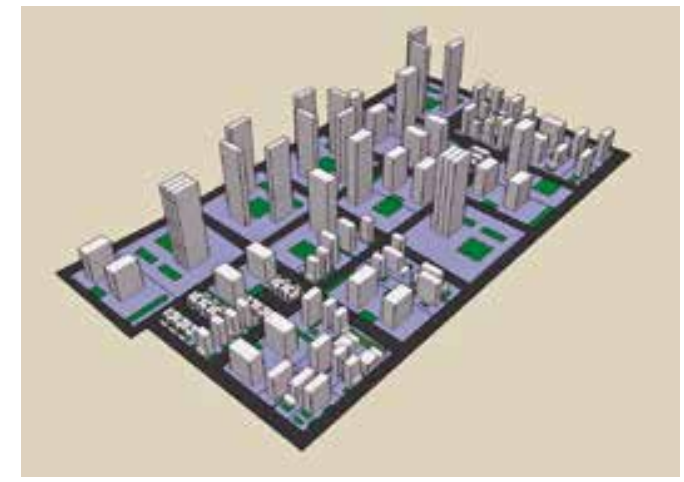

Figura 8 - Vila Romana. Simulação da Lei de Zoneamento de 2004. Coeficiente Máximo. Fonte: Acervo QUAPA

\section{TIPOS}

A partir do levantamento dos anúncios publicitários de conjuntos residenciais divulgados em São Paulo até o final de 2007 - catálogos de rua e de stands de vendas (acervo QUAPA), pesquisa nos sites de construtoras a incorporadoras e anúncios em jornais e revistas - iniciou-se a análise do projeto paisagístico para encontrar os tipos recorrentes de desenho dos espaços livres dos conjuntos. "O tipo é uma abstração em que se identificam as propriedades espaciais comuns a uma classe de edificações. $\bigcirc$ tipo não se refere, portanto, a um tipo ideal, nem a um tipo formal, mas a um padrão habitualmente produzido em uma época." ${ }^{5}$ Essa classificação em tipos não esgota toda a produção residencial vertical paulistana, mas sim traça um panorama de sua produção 6 . Tampouco sua manifestação na cidade ocorre da forma "pura" como apresentada aqui, mas sim, muitas vezes, com características de mais de um tipo combinados entre si.

Os conjuntos foram analisados sob o ponto de vista do seu porte, número de torres e implantação destas no terreno e disposição dos equipamentos de lazer e vegetação no conjunto residencial. De modo geral, observou-se a existência de uma fachada principal - a testada do lote ou a escolha de uma das fachadas - e a partir desta fachada principal um desenho semelhante a uma praça. Os equipamentos e áreas de lazer são alocados ao redor dos edifícios e nos recuos entre estes e os limites do conjunto. Os maiores equipamentos de lazer - piscinas e quadras - ficam ou no fundo do lote, quando o terreno é longitudinal, ou, em outros casos, as piscinas são dispostas no centro do conjunto (formando "complexos aquáticos", como são anunciados), mas sempre afastadas da fachada principal. Os exemplos apresentados a seguir são de conjuntos da área da Vila Romana, através de fotos ou desenhos, padrão QUAPA, realizados para estudo comparativo dos projetos:

Conjunto em uma torre, isolada no lote, com espaços de lazer ao longo dos recuos, como eixo de circulação longitudinal (figura 9). 


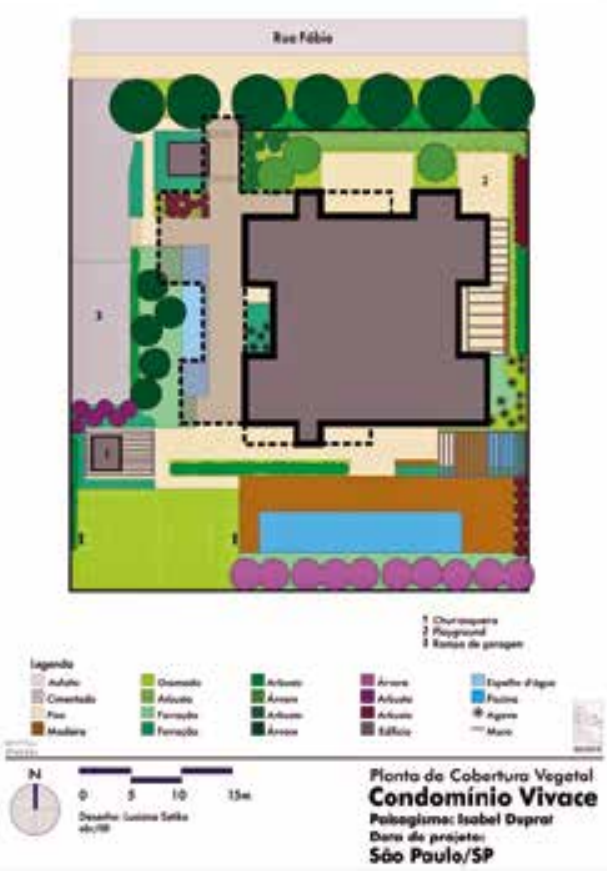

Figura 9

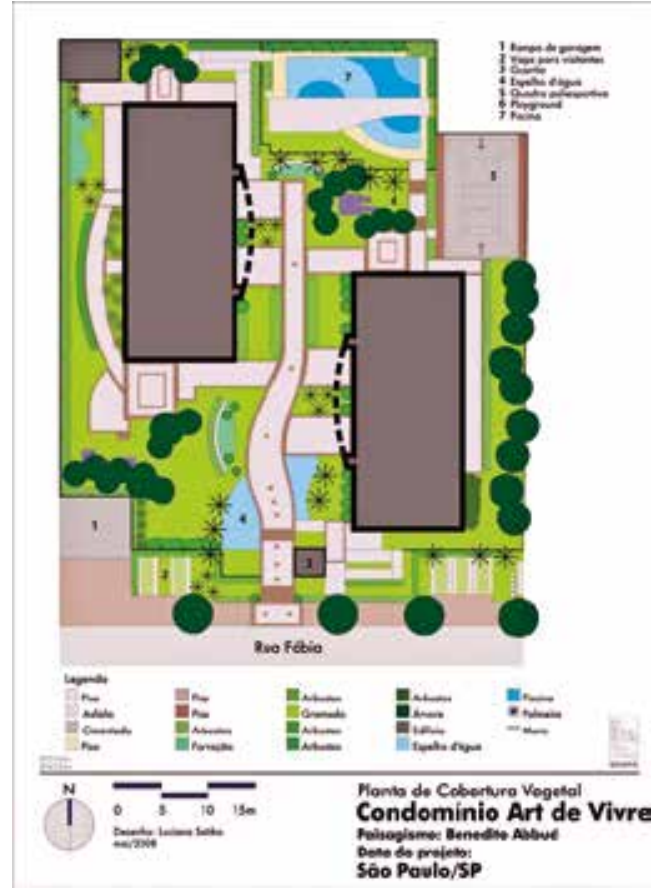

Figura 10

Conjuntos com duas torres, com eixo de circulação longitudinal entre elas e equipamentos de lazer alojados ao longo dos recuos, com circulação contornando os edifícios dando acesso a esses equipamentos (figura 10).

Conjuntos com distribuição simétrica das torres, com espaço com ideia de praça ou bosque central e equipamentos "atrás" das torres (figuras 11 a 15).

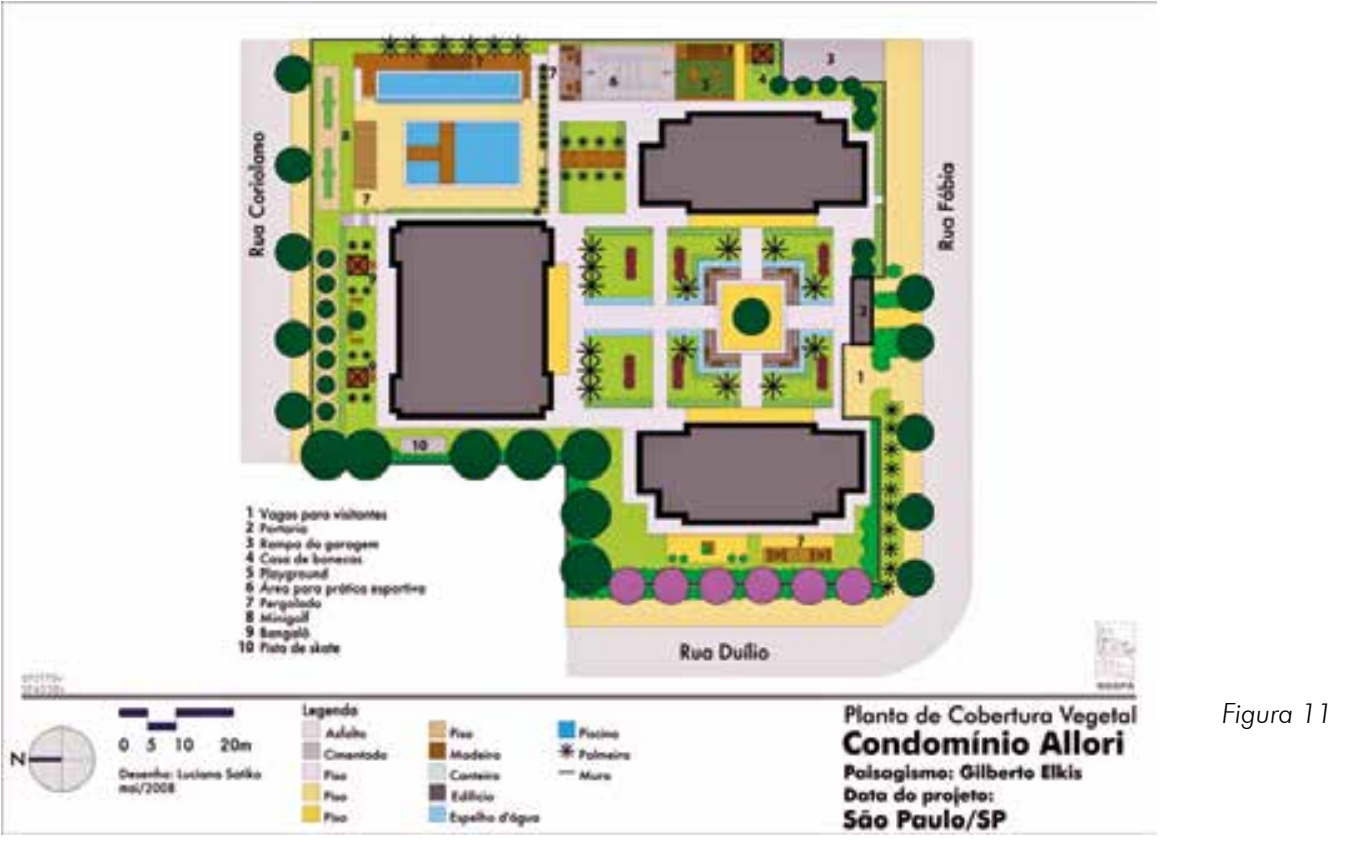




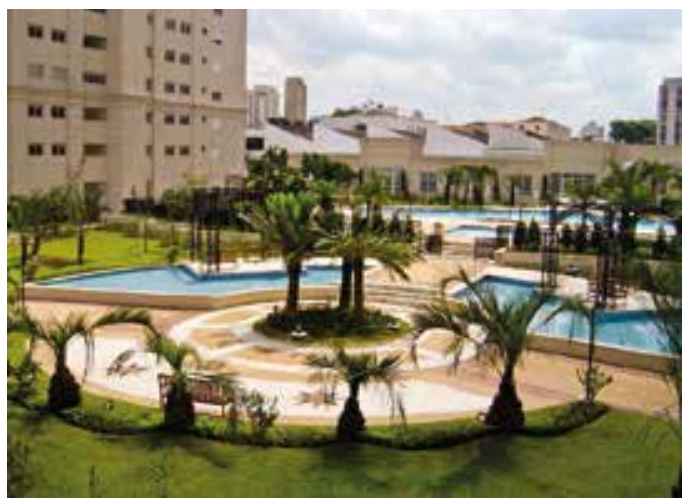

Figura 12

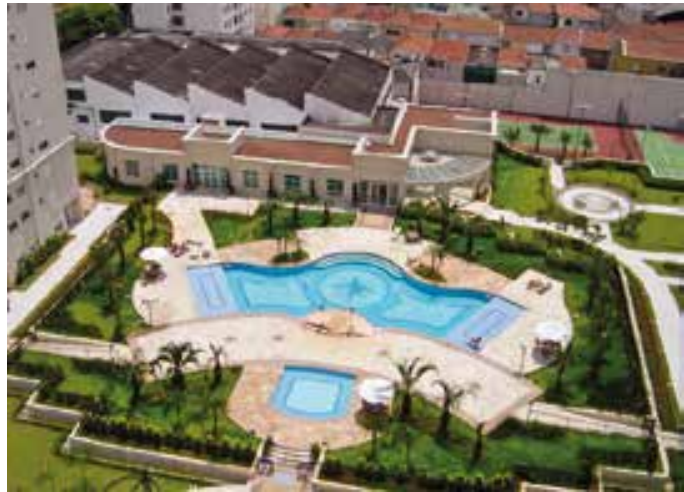

Figura 74

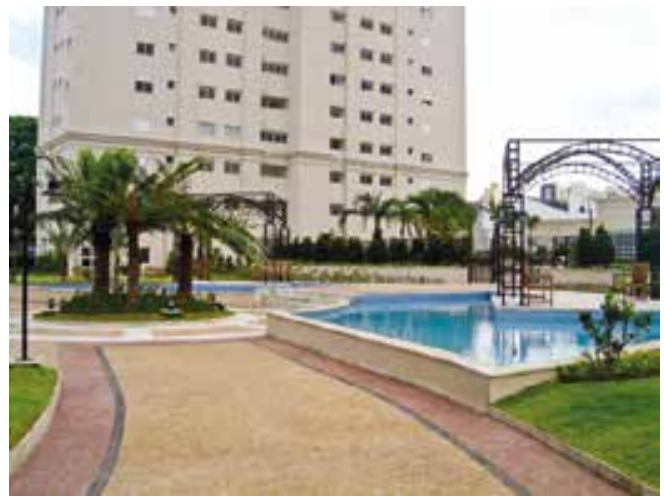

Figura 13

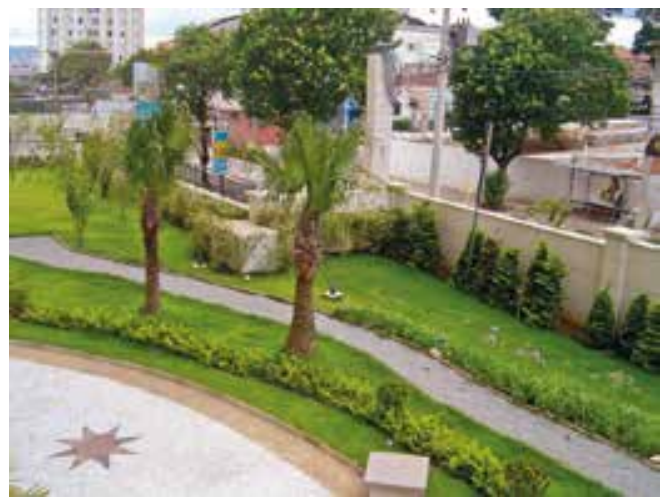

Figura 15

Figuras 11 a 15: Condomínio Paradiso Vila Romana. Fonte: Acervo QUAPA.

Terrenos longitudinais, que condicionam a uma distribuição em linha tanto das torres como dos equipamentos de lazer. A circulação, como nos outros casos, liga os equipamentos localizados ao redor dos edificios, mas também, é formada por caminhos que acompanham a maior dimensão do terreno. Essa configuração ocorre em áreas recentemente valorizadas pelo mercado imobilliário ao longo de avenidas ou ferrovias (figuras 16 a 20).

desenho dos espaços livres permanece tendo como determinantes as regras de ocupação do lote. Na forma mais comum, o da torre isolada no lote, o espaço livre é o resultante dos recuos obrigatórios do edifício, gerando jardins frontais e corredores com canteiros, espaços de recreação e estar. A mesma lógica ocorre em terrenos maiores, porém, há maiores possibilidades de implantação do(s) edifício(s), com ampliação do programa de lazer para fazer uso do térreo. Quão maiores as dimensões do terreno, maiores as possibilidades de desenhos dos espaços livres. 


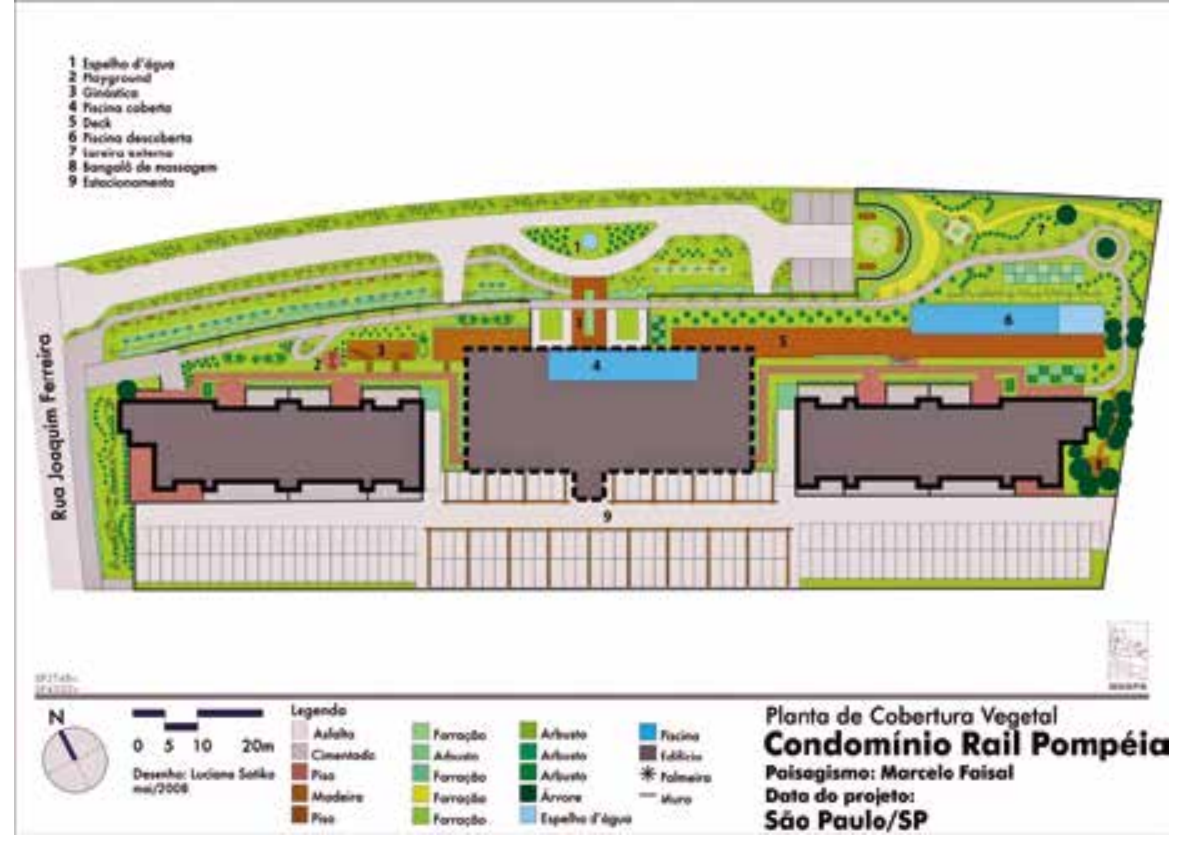

Figura 16
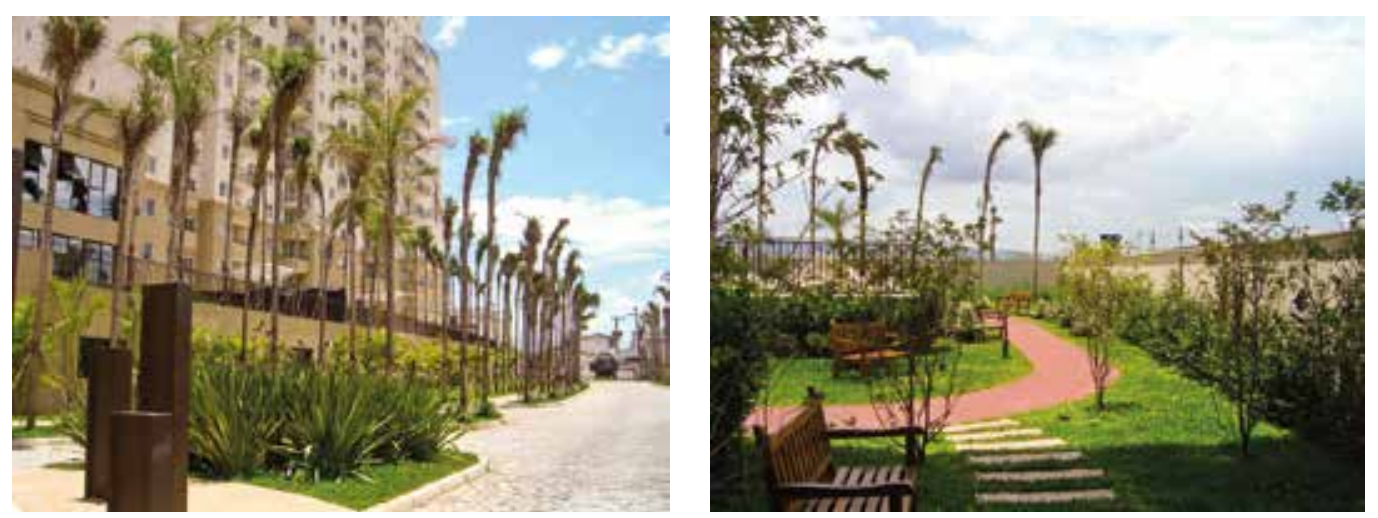

Figura 17

Figura 18
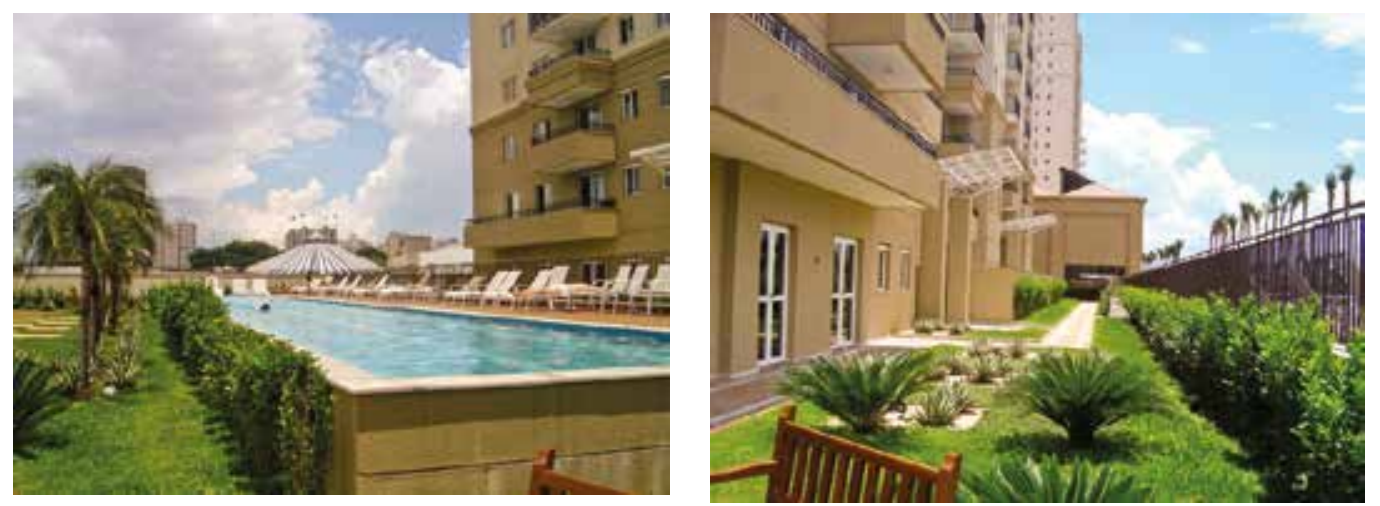

Figura 19

Figura 20

Figuras 16 a 20: Condomínio Raul Pompéia.

Fonte: Acervo QUAPA 


\section{CONSIDERAÇÕES}

Os grandes lançamentos, observados na cidade de São Paulo, apresentam o desenho de seus espaços livres semelhante a um clube ou de um bosque em meio aos edifícios. A implantação de conjuntos residenciais em grandes terrenos, a variedade de equipamentos de lazer e a alusão da "vida junto à natureza" devem ser entendidos como uma estratégia do mercado imobiliário diante do grande vulto de capital que vem recebendo para produzir retorno a esses investimentos.

Como resultado a este superequipamento das áreas privadas verticalizadas, em um flagrante processo de compensação das carências locais de espaços públicos, pode-se considerar tais áreas como de baixa demanda dos mesmos para recreação e lazer, apesar de por vezes serem apontadas como áreas carentes de tais equipamentos. Outra questão levantada foi o questionamento sobre a real utilização dos equipamentos e espaços de lazer e estar nos conjuntos residenciais pelos seus moradores. São equipamentos destacados nos anúncios publicitários e parecem importantes na decisão da compra de um imóvel. Porém, seria interessante analisar, o que não era o objetivo deste trabalho, a apropriação dos espaços livres desses conjuntos e as demandas reais de espaços livres e equipamentos de lazer nos espaços privados.

$\bigcirc$ estudo dos agentes da produção desse espaço, principalmente do poder público, através da legislação urbana e do mercado imobiliário, permite compreender a produção desses conjuntos e, assim, as condicionantes de desenho desses espaços. $\bigcirc$ aumento do porte dos conjuntos residenciais e a complexidade do programa de seus espaços livres trazem novas possibilidades de projeto, assim como novas formas de apropriação e percepção, tanto do espaço privado, como do espaço público e, por fim, da cidade.

\section{Notas}

1 A Pesquisa de Iniciação foi realizada entre 2006 e 2008, com análise de conjuntos residenciais verticais produzidos em São Paulo no período 1994 a 2007. Teve com objetivo, entre outros, dar continuidade a pesquisa de Iniciação Científica realizada por Francine Gramacho Sakata, que analisou o desenho dos espaços livres dos edifícios de apartamento em São Paulo até 1994.

2 Entrevista realizada com Prof. Dr. João Meyer, da Faculdade de Arquitetura de Urbanismo da Universidade da São Paulo.

3 Estudo realizado através da consulta ao catálogo QUAPA de anúncios de empreendimentos imobiliários residenciais (catálogos de rua e de stands de venda e imagens dos sites das construtoras e incorporadoras), principalmente os divulgados no ano de 2007.

4 Entre os distritos com os maiores percentuais de estoque residencial comprometido destacavam-se o Cambuci (100\%), Liberdade (97\%), Lapa (63\%), Rio Pequeno (42\%), Vila Leopoldina (40\%). Fonte: Apresentação de Nilza Souza Antenor. Ciclo de Palestras QUAPASEL - novembro de 2007.

5 VAZ, Lilian. In: MENEH, Marcia. Morfologia da Paisagem Verticalizada: Conflitos e padrões urbanísticos. 1997. Dissertação (Mestrado) - Faculdade de Arquitetura e Urbanismo da Universidade de São Paulo. 1997. p. 32 e 33 .

6 São referências os trabalhos de Silvio Soares Macedo, de 1984, e de Solange Aragão, de 2005. Ambos classificaram os conjuntos residencias verticais paulistanos em tipos. Assim, alguns dos tipos apresentados aqui são iguais aos identificados por eles e outros são novas configurações, observadas durante a realização desta pesquisa. 


\section{Bibliografia}

ARAGÃO, Solange Moura Lima de. Espaços livres urbanos: A produção da caracterização das áreas de uso comum dos conjuntos de edifícios de apartamentos paulistanos (1990-2004). 2005. Tese (Doutorado) - Faculdade de Arquitetura e Urbanismo da Universidade de São Paulo. São Paulo. 2005.

BARBON, Ângela Luppi. Mercado formal privado. In: Mobilidade residencial intraurbana em grandes centros: RMSP. 2003. Dissertação (Mestrado em Urbanismo) - Pontifícia Universidade Católica de Campinas. Orientador: Raquel Rolnik. Campinas. 2003.

FERREIRA, Nadia Somekh M.. A (des)verticalização em São Paulo. 1987. Dissertação (Mestrado) - Faculdade de Arquitetura e Urbanismo da Universidade de São Paulo. São Paulo. 1987.

MACEDO, Silvio Soares. Quadro do Paisagismo no Brasil. São Paulo: Edição do autor, 1999. (Coleção Quapá.)

São Paulo, paisagem e habitação verticalizada. Os espaços livres como elemento de desenho urbano. 1987. Tese (Doutorado) - Faculdade de Arquitetura e Urbanismo da Universidade de São Paulo. São Paulo. 1987.

MAGNOLI, Miranda M. E. M.. Espaços livres e urbanização: Uma introdução a aspectos da paisagem metropolitana. São Paulo: FAUUSP, 1983.

MENNEH, Márcia Unti Halluli. Morfologia da paisagem urbana verticalizada: Conflitos e padrões urbanísticos. 1997. Dissertação (Mestrado) - Faculdade de Arquitetura e Urbanismo da Universidade de São Paulo. São Paulo. 1997.

SAKATA, Francine Gramacho. As linhas projetuais da arquitetura paisagística no desenho dos espaços livres nos edifícios de apartamentos. 1994. Relatório (Iniciação Científica). Faculdade de Arquitetura e Urbanismo da Universidade de São Paulo/ FAPESP. São Paulo. 1994.

SÃO PAULO. Prefeitura do Município de São Paulo. Secretaria de Planejamento Urbano. Plano Diretor Estratégico do Município de São Paulo 2002-2012. São Paulo: Editora Senac/ Prefeitura Municipal de São Paulo, 2002.

Secretaria de Planejamento Urbano. O novo zoneamento ao alcance de todos. São Paulo: Prefeitura Municipal de São Paulo, 2004.

Lei n. 13.430 de 2002.

Lei n. 13.885 de 2004

SOUZA, Maria Adélia Aparecida de. A identidade da metrópole: A desverticalização em São Paulo. São Paulo: Hucitec/ Edusp, 1994.

VILLA, Simone Barbosa. Apartamento metropolitano: Habitações e modos de vida na cidade de São Paulo. 2002. Dissertação (Mestrado). Orientador: Prof. Dr. Marcelo Tramontano. - Escola de Engenharia de São Carlos da Universidade de São Paulo. São Carlos. 2002.

O produto imobiliário paulistano. Uma crítica à produção de apartamentos ofertados no merrcado imobiliário a partir de 2000. In: Morar em Apartamentos: A produção dos espaços privados e semiprivados nos apartamentos ofertados pelo mercado imobiliário no século XXI, na cidade de São Paulo. Critérios para Avaliação Pós-Ocupação comportamental. 2008. Tese (Doutorado) - Faculdade de Arquitetura e Urbanismo da Universidade de São Paulo. São Paulo. 2008.

VILLAÇA, Flávio. Espaço intraurbano no Brasil. São Paulo: Studio Nobel, 2001. 
